\title{
Aproximación AL PROBLEMA DE LA CLASIFICACIÓN DE LA SEÑALIZACIÓN DE YURI KNÓROZOV
}

\author{
Galina Yershova \\ Alejandro Sheseña Hernández
}

\section{Nota de los traductores}

En las siguientes líneas presentamos por vez primera en español el artículo del historiador, mayista y lingüista ruso Yuri Knórozov titulado "Aproximación al problema de la clasificación de la señalización"1, aparecido originalmente en ruso en 1973 en el volumen denominado "Principales problemas de la Africanística", publicado por la Editorial Nauka de la extinta Unión Soviética (Ю. В. Кнорозов. К вопросу о классификации сигнализации//Основные проблемы африканистики. Этнография. История. Филология. К 70-летию членакорреспондента АН СССР Д. А. Ольдерогге. М., Наука, 1973. C. 324-334). ${ }^{2}$
Galina Yershova. Doctora en Historia por el Instituto de Arqueología de la Academia de Ciencias de Rusia. Directora del Centro de Estudios Mesoamericanos de Moscú "Yuri Knórozov". Directora del Centro Xcaret Knórosov de Lengua y Epigrafía Maya. Correo electrónico billyfelixfox@hotmail.com Alejandro Sheseña Hernández. Doctor en Historia por la Universidad Estatal de Voronezh (Rusia) y el Centro de Estudios Mesoamericanos de Moscú "Yuri Knórozov". Docente-investigador de la Universidad Autónoma de Chiapas. Correo electrónico: sesena@hotmail.com
$\mathrm{E}$ n el artículo, el autor, reconocido por haber descifrado la escritura jeroglífica maya a principios de la década de los 50's del siglo $\mathrm{XX}$, examina los principios generales de los sistemas de señalización usados por los animales y los seres humanos. Sobre estos últimos, los más complejos, Knórozov detalla cuáles son los dos tipos de señalización humana y la manera como operan. En el primer tipo, neutro, predomina el contenido de la señal, mientras que en el segundo, fascinante, el papel principal lo juegan las propiedades. La señalización, en cualquier caso, funciona como medio para asegurar las relaciones funcionales entre los miembros del colectivo humano.

El propósito que persigue el autor es explicar el comportamiento social a través de la definición del papel que juega la información y sus medios de transmisión y fijación en los procesos universales de desarrollo civilizatorio. Knórozov de esta manera proporciona una herramienta fundamental para aquellos estudiosos interesados en los problemas de análisis semiológico general. Para el caso de México es de singular importancia esta obra dada la larga tradición de uso de signos, imágenes y símbolos presente en la cultura de nuestro país a través de la historia.

Galina Yershova y Alejandro Sheseña 
Aproximación al problema de la clasificación de la señalización

Yuri Knórozov

0.1. La posibilidad de que surjan y subsistan señales presupone la existencia de un sistema diferenciado compuesto de unidades poseedoras de determinadas cualidades.

Por sistema se sobreentiende cierto conjunto de unidades materiales que posee determinada orientación, es decir, que es relativamente independiente del medio circundante.

El propio hecho del surgimiento, existencia y destrucción de un sistema es el resultado de relaciones generales y de interdependencias. El sistema representa una esfera de intensa relación recíproca. El aumento de la relación (interdependencia) entre las unidades del sistema puede ser interpretado en general como el perfeccionamiento de la organización (fenómeno llamado en ocasiones neguentropía), mientras que la disminución de la relación, como el aumento de la entropía. Entre más organizado esté el sistema, menos dependerá del medio circundante y más influirá sobre él. Dicho de otra manera, mientras más alta sea la organización del sistema, es mayor el "grado de libertad" de este sistema en relación al medio circundante y, consecuentemente, menor es el "grado de libertad" de sus componentes.

Cabe señalar que la intensificación en la organización del sistema no siempre significa el aumento de su estabilidad. En condiciones de cambios rápidos del medio circundante los sistemas con cierta autonomía ("grado de libertad") en sus componentes pueden resultar más estables que los sistemas con una organización sumamente alta. Al parecer, para una mayor estabilidad del sistema se requiere de un mínimo determinado de organización, de lo contrario se reduce la estabilidad.

Los componentes materiales del sistema pueden ser homogéneos, sin embargo, al aumentar la organización adquieren diversos rasgos, es decir, se especializan. La especialización desmesurada (irreversible) de las unidades integrantes del sistema acrecienta la organización pero disminuye su estabilidad.

En el marco de un determinado sistema estable, sus componentes pueden o no mudarse regularmente, lo que abre la posibilidad de un desarrollo rápido en condiciones de activa interacción con el medio circundante.

Conforme se desarrolla el sistema, crece la cantidad de componentes. Si la cantidad de unidades supera cierto mínimo, entonces la estabilidad del sistema comienza a disminuir.

La unidades materiales integrantes del sistema pueden estar unidas entre sí (sistema integrado) o pueden estar separadas en el espacio (sistema diferenciado). Los sistemas integrado y diferenciado se encuentran relacionados genéticamente. Por naturaleza, en los sistemas en desarrollo la cantidad de componentes crece. Cuando el crecimiento de la cantidad de unidades lleva a la pérdida de estabilidad del sistema integrado, surge un sistema diferenciado de grado más alto con sistemas integrados en calidad de componentes.

El desarrollo del sistema prevé el aumento de la cantidad de unidades integrantes y el aumento de la organización. Estas dos tendencias se encuentran en contradicción ya que el aumento de la cantidad de unidades dificulta la organización. Los sistemas dinámicos se caracterizan por un desarrollo acelerado. El desarrollo del sistema, lento en las primeras etapas, aumenta a continuación su velocidad hasta determinado mínimo (que al ser excedido amenaza la estabilidad del sistema), después de lo cual sobreviene un salto cualitativo. La reproducción del sistema ya formado se efectúa en orden inverso, es decir, el desarrollo se demora. De esta forma, la "ley de Haeckel", por ejemplo, se puede formular de la siguiente manera: la ontogenia recapitula la filogenia a velocidad inversamente proporcional.

Todos los sistemas de la naturaleza animada e inanimada responden a leyes generales válidas en el Universo ("sistema universal"). La ley principal para todos los sistemas es la tendencia hacia el desarrollo desde las formas primitivas hasta las complejas. El desarrollo 
puede ser interpretado como la adquisición en cierta medida de algunas cualidades del "sistema universal" por parte de un sistema dado.

El surgimiento de un sistema de orden superior como resultado del salto cualitativo lleva a la aparición de nuevas propiedades, las cuales, naturalmente, no pueden reducirse a las propiedades de las unidades integrantes del sistema. Así, las propiedades de las partículas elementales no son idénticas a las propiedades del átomo como sistema diferenciado básico de la naturaleza inanimada. Asimismo, las propiedades de los sistemas integrados superiores -moléculas, cristalesno son la suma de las propiedades de los átomos que los componen. A cada nivel le corresponden sus peculiaridades y sus leyes de desarrollo.

En las condiciones de nuestro planeta el sistema integrado más alto por organización es el organismo vivo. La señalización es un elemento necesario de un sistema diferenciado cuyas unidades son organismos vivos poseedores de un aparato de dirección bastante desarrollado y de un mecanismo de movimiento (por lo general estos son los articulados y los cordados).

0.2. La señalización en las asociaciones de animales garantiza la coordinación de las acciones de los miembros de la asociación. Entre los mamíferos las asociaciones tienen diferente composición, estructura y grado de organización. Sin embargo, todas las asociaciones de animales se caracterizan por su homogeneidad, ya que los individuos que las componen son miembros únicamente de una asociación dada, lo que por supuesto no evita la fluctuación de esos miembros dentro de la asociación.

La asociación de personas no representa desarrollo ulterior o forma superior a la unión de animales, sino es el tipo siguiente del sistema diferenciado, es decir, la unión de las uniones. La unidad componente de la asociación humana (que no coincide con la sociedad) no es el individuo, sino el colectivo. Debido a esto, la señalización en la asociación humana es de tipo superior en comparación con la señalización en las uniones de animales, y adquiere propiedades y funciones cualitativamente distintas.

En relación a la señal entre los miembros de la asociación, hay que distinguir al inductor (quien emite la señal), al destinatario (a quien se dirige la señal), al testigo (quien casualmente recibe la señal) y al interceptor (quien premeditadamente intercepta la señal destinada a otro miembro de la asociación). Por lo general hay solo un inductor. El destinatario frecuentemente es múltiple, es decir, la señal se dirige al conjunto de miembros de la asociación.

0.3. La señal se emite con ayuda del esfuerzo muscular y representa una variedad especial de acción.

Por acción se sobreentiende no cualquier movimiento biológico, sino una serie de movimientos musculares libres que tienen un propósito definido (por ejemplo, tomar algo, morder). La serie de acciones con un propósito final común constituye una operación (por ejemplo, capturar una presa, construir una guarida).

Entre los miembros de la asociación que realizan conjuntamente una operación se establece una relación, es decir, una dependencia correlativa de las acciones de un miembro de la asociación con respecto a las acciones de otro. En determinadas condiciones la relación puede tornarse funcional, en particular cuando la acción de un miembro de la asociación origina en el otro una acción precisa.

Inicialmente las señales surgen para asegurar las relaciones existentes al momento de ejecutar conjuntamente las operaciones. En este caso la señal puede ser interpretada principalmente como la reacción a la carencia de una acción adecuada en otro miembro de la asociación (obviamente, en condiciones de total sincronización de acciones conjuntas la señalización no es necesaria).

Una parte de las señales más frecuentes en el mundo animal está relacionada no con la asociación, sino con el entorno ecológico; como ejemplo está la señal de peligro (rugido, silbido), la cual tiene como objetivo detener al agresor. 
0.4. La señal es una acción que provoca la acción de otro miembro de la asociación. Por sí sola la señal no tiene relación alguna con la operación que se está realizando y puede únicamente estorbar al inductor. De esta manera, aunque la señal es una de muchas acciones diferentes en la realización conjunta de una operación, se diferencia por principio de otras acciones utilitarias.

Habiendo aparecido al principio sobre la base de las relaciones existentes y para su propio aseguramiento, las señales con el tiempo sirven como medio de establecimiento y mantenimiento de nuevas relaciones entre los miembros de la asociación. De este modo, las señales son una variedad especial de acciones que aseguran tanto la coordinación de las acciones comunes (utilitarias) de los miembros de la asociación como también la dirección de la asociación misma.

La correlación entre los elementos principales (acción-relación-señal) en las asociaciones de animales puede ser presentada de la siguiente manera:

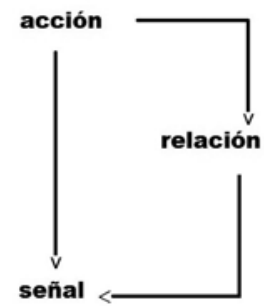

Las acciones conjuntas llevan a la aparición de relaciones (dependencia correlativa) entre los miembros de la asociación, y las relaciones a su vez provocan la aparición de una variedad especial de acciones-señales (acciones que provocan acciones).

0.5. La señal puede ser interpretada como un caso particular de empleo de fuerza física.

Es fácil encontrar ejemplos de semi-señales. Así, por ejemplo, para hacer caminar a alguien se le puede empujar con distintos grados de fuerza.

Sin embargo, la mayoría de las señales en los grupos de animales tiene un origen totalmente diferente: éstas están relacionadas con diferentes acciones suplementarias y movimientos semi-libres que acompañan a la realización conjunta de las operaciones (por ejemplo, los así llamados ruidos vitales en la esfera de la señalización sonora).

0.6. La posibilidad de la aparición de la señalización está condicionada por determinadas cualidades orgánicas de los miembros de la asociación, o siendo más exactos, está condicionada por los órganos de los sentidos, los cuales permiten recibir señales a distancia. En relación a esto, es necesario marcar claramente las diferencias entre la señal activa (emitida por el inductor) y todas las demás sensaciones percibidas por los sentidos del destinatario.

Cualquier irritante que provoque sensaciones de una u otra forma actúa sobre el organismo, aunque el efecto de muchos irritantes es prácticamente neutro. Cualquier irritante además de su influencia directa puede (por lo menos en teoría) sustituir a otro irritante después de una serie de combinaciones, es decir, puede volverse irritante condicional (señal objetiva) y provocar una reacción libre (reflejo condicional), aproximadamente la misma reacción que podría ser provocada por el irritante directo sustituido. De esta manera, cualquier irritante condicional provoca dos reacciones: la primera como irritante directo y la segunda como sustituto de otro irritante directo.

La señal activa emitida por el inductor es para los sentidos del destinatario uno de los muchos irritantes y puede ser considerada como cierta variedad de irritante condicional provocante de reflejos condicionales.

Sin embargo, aunque el mecanismo de reflejos condicionales se usa ampliamente en la señalización de los grupos de animales, existe una diferencia sustancial entre la señal activa y el irritante condicional.

El irritante condicional provoca una reacción espontánea del organismo, pero no necesariamente se refleja en la conducta del miembro del grupo. La señal tiene como objetivo provocar una determinada reacción, inducir al destinatario a realizar una determinada acción. Generalmente la señal es una orden, la cual, sin 
embargo, no siempre se cumple, es decir, no se refleja. En la realización conjunta de una operación los sentidos de cada miembro de la asociación perciben una gran cantidad de irritantes directos y condicionales, la mayor parte de los cuales distrae al miembro de la realización de la operación. La señal precisamente se dirige contra estas interferencias para asegurar la realización exitosa de la operación.

En los reflejos condicionales surgidos naturalmente, el irritante condicional sustituye a un determinado irritante directo concreto. Así, por ejemplo, un tipo concreto de alimento origina ideas definidas sobre las sensaciones de gusto involucradas. La señal en las asociaciones de animales, por el contrario, siempre es sintetizada (frecuentemente hasta el extremo) y nunca designa a un irritante concreto. Por ejemplo, la señal de llamado a la comida nunca da indicación sobre el carácter de la comida.

0.7. La señal en los grupos de animales representa la forma material de la comunicación. La comunicación por lo regular se realiza en forma de órdenes (abiertas o escondidas). La señal transmite comunicación acerca de una situación, incluyendo sucesos (como casos particulares de la situación). En muchos casos la comunicación acerca de una situación (suceso), por ejemplo el acecho de un enemigo, funciona al mismo tiempo como una orden (por ejemplo “ipeligro!”)

La comunicación sobre la situación se hace, por regla, a través de una sola señal. En la señalización acústica esta señal consiste en un conjunto de sonidos agrupados alrededor de una señal "silábica", la cual puede ser articulada prolongadamente.

Al mismo tiempo, es importante subrayar que en la señalización de los animales se puede encontrar la duplicación de señales. En este caso cada señal conserva su significado, sin embargo, uno de estos significados se usa como una especie de determinativo; por ejemplo, la señal por la que la gata llama a sus gatitos se compone de un breve ronroneo que se transforma en maullido (“llamado benévolo").
Se encuentran casos de intercepción de las señales en las asociaciones de animales. Así, por ejemplo, el tigre imita la llamada de celo del venado para engañar a su presa. Según algunos cuentos, cuando el lobo se mete a la pocilga imita el gruñido de los cerdos para calmar a los cochinitos.

1.1. El paso desde la asociación hacia el tipo superior del sistema diferenciado (“asociación de asociaciones"), que llevó a la aparición del colectivo humano en calidad de unidad componente, exigió una apropiada señalización de nivel más alto.

En la señalización humana, es decir, en el lenguaje acústico, el contenido de la comunicación también es una situación, aunque dividida en tres partes integrantes (trí́da):

\section{sujeto-acción-objeto}

No son miembros de la tríada el atributo y la circunstancia ya que la introducción de éstos no altera la comunicación sobre la situación, sino únicamente da información complementaria.

El desmembramiento de una situación en una triada exigió una considerable cantidad de nuevas señales para transmitir comunicaciones. Teóricamente podían haber dos principales vías técnicas para ello: aumentar la cantidad de señales del tipo previo, o bien duplicar (juntar) las señales ya existentes; en este caso el par adquiría un nuevo significado. En la práctica sólo fue posible la segunda vía ya que los órganos de articulación y oído no permitieron aumentar considerablemente la cantidad de señales comunes. Al final el par de señales (cada una de los cuales previamente transmitía una situación) comenzó a designar a un elemento de la tríada.

La aplicación del principio de ensamblaje (duplicación) permitió crear un nuevo tipo de señalización, es decir, la lengua, con un enorme excedente. La reserva potencial de posibles combinaciones no sólo alcanzó a resolver las demandas inmediatas sino también las del futuro lejano. 
1.2. En el momento de aparición de la lengua se aplicaba únicamente la duplicación. Las nuevas unidades creadas correspondían a la mínima unidad semántica, es decir, al morfema moderno aproximadamente. De esta manera cada morfema inicialmente representaba un binomio (incluyendo por supuesto el elemento nulo).

Considerando que en cualquier lengua la cantidad de morfemas usados sincrónicamente es de unos 1600 , se puede suponer que la cantidad de señales iniciales que sirvieron de material para la lengua fue de 40 (lo que corresponde aproximadamente a la cantidad de señales en las asociaciones de antropoides).

Aquí la transposición de los componentes del binomio, al parecer, no debe considerarse, ya que lo más probable es que en las etapas tempranas tal transposición no se percibía (sobre lo que atestigua la transposición en la etapa formativa del habla de los niños).

Las unidades iniciales de la lengua, desde luego, no eran morfemas en el sentido actual de la palabra; se convirtieron en tales en el transcurso del desarrollo de la lengua al usar el mismo principio de ensamblaje, es decir, al surgir las palabras.

Desde el punto de vista fonético, las unidades iniciales de la lengua tienen poco común con los morfemas actuales (debido por lo menos a las diferencias en los órganos de articulación). Después, en el transcurso del desarrollo de la lengua, la composición fonética de los morfemas, por lo que se puede juzgar, cambió totalmente varias veces.

1.3. El tránsito hacia la señalización de tipo totalmente nuevo, en la cual la situación se transmite no a través de una señal, sino a través de una serie de señales con desmembramiento de la situación en una tríada (sujetoacción-objeto), condujo a la aparición de características absolutamente nuevas en la señalización.

El desmembramiento de la situación dio la posibilidad de que se separara de ella la serie de señales. Antes de ello la señal podía corresponderse sólo con la situación sincrónica. Ahora la serie de señales también podía comunicar acerca de situaciones anteriormente ocurridas o por ocurrir en el futuro.
El desmembramiento de la situación condicionó la posibilidad de modelarla, es decir, comunicar sobre una situación ya ocurrida, que podría haber ocurrido, o que jamás podría realizarse. Este efecto se obtuvo de manera muy simple: sustituyendo los elementos de la tríada.

Debido a esto, la principal función de la nueva señalización (el lenguaje) pasó a ser modeladora (además de la comunicativa previa). El razonamiento, es decir, la reproducción interna (muda) de la serie de señales, es por lo general una modelación de situaciones. Justamente la función modeladora de la señalización humana dio la posibilidad de planificar con anticipación las operaciones, incluso aquellas que jamás se habían realizado antes.

2.1. La señal (la serie de señales), así como los irritantes condicionales, funciona de doble manera. En calidad de señal es transmisora de información sobre una situación (una orden). Al mismo tiempo es un determinado hecho físico que afecta los sentidos, un irritante directo (y a veces condicional, con excepción de la información). Esta dualidad de la señal, así como la posibilidad de modificarla en un diapasón suficientemente amplio sin cambiar la información, dio el sustento para utilizar sus propiedades físicas (como irritante para elevar la probabilidad del cumplimiento de la orden).

El analizador del destinatario se encuentra en diferentes condiciones dependiendo de los irritantes internos y externos. Algunos irritantes, sobre todo los rítmicamente repetitivos, Ilevan a una cierta inhibición del analizador. Este efecto (fascinación) se usa ampliamente para dormir al destinatario y llevarlo al estado del sueño hipnótico. Este último, incluye varias fases: somnolencia, fascinación, sonambulismo y catalepsia. En la fase de la fascinación el analizador deja de percibir los irritantes que afectan a los receptores, excepto las señales del inductor.

El mecanismo de influencia de la fascinación se suele explicar por la ley de la irradiación. La influencia se difunde poco a poco a través del receptor sobre un sector del analizador, con excepción del "punto de 
control" a través del cual se realiza el contacto con el inductor (informe). Es importante resaltar que la relación entre el inductor (hipnotizador) y el destinatario en estado de fascinación o sonambulismo se aproxima a la relación funcional, es decir, el destinatario ejecuta cualquier tipo de órdenes normales con excepción de aquellas que se oponen totalmente a la práctica de su colectivo.

En el estado de vigilia comúnmente se suceden con rapidez diferentes microfases (generalmente relacionadas con las emociones), algunas de ellas en uno $u$ otro grado recuerdan las fases hipnóticas iniciales (somnolencia, fascinación). La duración mínima de la microfase es, por lo visto, equivalente al tiempo del trabajo "silencioso" del cerebro (milésimas de segundos). El tránsito de una microfase a la otra puede ser provocado por un irritante rítmico continuo o también por un irritante chocante inesperado.

2.2. La probabilidad del cumplimiento de la orden recibida por un destinatario que se encuentra en una microfase cercana al estado de fascinación por supuesto aumenta considerablemente. Por ello en la señalización se usan ampliamente las propiedades físicas de la señal como irritante fascinante.

En los grupos de animales muchas señales (por ejemplo, la llamada de una gata buscando gato) se repiten muchas veces con un breve intervalo. Tal repetición de la orden, por una parte, es controlada o redundante (hasta que la escuche el destinatario) y, por la otra, tiene determinadas propiedades fascinantes debido a su estructura rítmica. Estas propiedades (de efecto graduado o repentino "chocante") son propias de la mayoría de las señales en las asociaciones de animales.

2.3. La señalización humana con series largas es muy cómoda para el uso de métodos fascinantes, en particular para la organización rítmica. Al parecer, uno de los métodos más antiguos fue la prolongación de las vocales (canto glissando, melopea). La organización rítmica de la serie de señales acústicas se conseguía por diferentes medios, entre ellos la repetición de las acentuaciones (incluso violando las aceptadas) o la repetición de los fonemas (prosa ritmada), o combinando uno con otro (versos ritmados).

Sin embargo, al someter reiteradamente al analizador a una determinada irritación ritmada, deja de percibirla (como el tic-tac permanente de los relojes de pared), lo que evidentemente se puede calificar como una "defensa contra la inhibición (defensa antirepercutiva)". La serie de señales de estructura estrictamente rítmica puede, de manera semejante, perder sus propiedades fascinantes después de varias repeticiones. Para combatir la "defensa contra la inhibición" se han utilizado ampliamente varias alteraciones del ritmo monótono, por ejemplo, las pausas en los versos (naturalmente, en la declamación, y aún más en el canto, las propiedades fascinantes se intensifican bruscamente).

Evidentemente, las propiedades fascinantes de la serie de señales no pueden ser valoradas en unidades de información. Como ya se mencionó, las propiedades fascinantes están relacionadas con el irritante directo y no con la señal. La unidad técnica natural para medir la estructura rítmica es el compás o la rima, es decir, la unidad mínima rítmica. La unidad principal representa un cierto mínimo de unidades rítmicas suficiente para trasladar al destinatario de una microfase a otra (estrofa, copla, melodía).

La señalización humana moderna en sus dos variedades principales (acústica y visual) se puede subdividir en neutra, donde el papel dominante lo juega la información (la razón de la comunicación), y fascinante, en la cual el papel principal lo juega la fascinación (las propiedades de la serie de señales). El criterio más simple para remontar hacia la segunda de estas subdivisiones es el deseo del destinatario de recibir dos o más veces la misma comunicación (por ejemplo, volver a escuchar una canción ya conocida).

De acuerdo con la práctica actualmente existente, lo más útil es distinguir cinco subdivisiones (dispuestas simétricamente): 


\begin{tabular}{|c|c|c|c|c|}
\hline & $\begin{array}{l}\text { Información } \\
\text { (contenido) }\end{array}$ & $\begin{array}{l}\text { Fascinación } \\
\text { (propiedad) }\end{array}$ & $\begin{array}{c}\text { Señalización } \\
\text { acustica }\end{array}$ & $\begin{array}{c}\text { Señalización } \\
\text { visual }\end{array}$ \\
\hline 1 & Funciona & Neutra & El habla & Texto \\
\hline 2 & Funciona & Funciona parcialmente & Entonación & Caligrafía \\
\hline 3 & Funciona & Funciona & Declamación & Cartel \\
\hline 4 & $\begin{array}{l}\text { Funciona } \\
\text { parcialmente }\end{array}$ & Funciona & Canto & Pintura \\
\hline 5 & Neutra & Funciona & Música & Ornamento \\
\hline
\end{tabular}

La primera subdivisión está representada por los textos impresos, cuya tipografía es prácticamente neutra. El habla sin entonación prácticamente no existe aunque hay casos en los que la entonación es muy débil. El discurso monótono posee determinadas propiedades fascinantes.

La segunda subdivisión predomina en la vida cotidiana en forma de discursos más o menos bastante entonados, y también en forma de textos manuscritos (cartas, notas), ya que la forma de la letra produce cierta influencia. Sin embargo, el papel más importante lo juega la información, es decir, la razón de la comunicación

La tercera subdivisión se caracteriza por el equilibrio de información y fascinación. Esta subdivisión es escasa en la vida cotidiana ya que el discurso de una persona muy emocionada (o de la que simula estar emocionada) frecuentemente adquiere una estructura rítmica (fascinación espontánea). La tercera subdivisión se usa ampliamente en distintas ocasiones solemnes (por ejemplo, en la misa de la iglesia). La variedad gráfica correspondiente (propia de la antigua pictografía) se usa ampliamente en la propaganda.

La cuarta subdivisión se caracteriza por el predominio de la fascinación. El contenido de la comunicación por lo regular ya es conocido por el destinatario. En la vida cotidiana se utiliza ampliamente en forma de canciones no sólo para la fascinación, sino también para la autofascinación (llevándose a sí mismo a una determinada microfase).
Con el surgimiento del Estado este medio queda en las manos de los maestros profesionales y se usa activamente para la propaganda.

La quinta subdivisión pierde casi o totalmente su carácter de señal, es decir, estando dotada de propiedades fascinantes no transmite ninguna información. Se utiliza ampliamente para crear cierto ambiente general o preámbulo.

2.5. La señalización fascinante, como aseguradora de relaciones casi funcionales, tiene un papel importante y representa (como la señalización en general) un elemento inseparable del colectivo. Por eso los intentos de prohibir parcialmente la señalización fascinante (surgidos en momentos de cambios de religión) han resultado imposibles y únicamente han provocado la aparición de nuevas formas de esta señalización.

Aunque la fascinación se emplea mucho en la esfera del arte, este último de ninguna manera debe reducirse a la fascinación. El objetivo del arte es por lo común crear una imagen (menos frecuente es crear una situación), es decir, crear en el destinatario una idea acerca de una persona que puede servir de patrón positivo o negativo adecuado para seguirlo, imitarlo o proyectarlo. Para crear una idea sobre una persona es necesario escoger una situación (momento focal) que pudiera dar la correspondiente característica. En la vida cotidiana el momento focal que cambia la idea sobre una persona por lo general acontece inesperadamente y a menudo está relacionado con una situación poco significante. En la esfera del arte únicamente los maestros logran encontrar 
la situación que puede servir de momento focal para cambiar la idea acerca de la persona.

Si el momento focal es elegido exitosamente, en el receptor aparece una idea adecuada de la persona incluso cuando el maestro no aplicó o casi no aplicó técnicas fascinantes. Al contrario, si la situación no representa un momento focal, entonces en el receptor no aparece la idea adecuada, independientemente de cuales técnicas fascinantes se hayan utilizado. De esta manera en el arte se emplea la fascinación, pero el arte no se reduce a la técnica de la fascinación, con excepción de ciertas variedades (por ejemplo, la ornamentación).

\section{Notas}

${ }^{1}$ Traducción del ruso al español de Galina Yershova y Alejandro Sheseña.

2 Los traductores agradecen al Centro Knórozov Xcaret de la Lengua y Epigrafía Maya y al Ing. Marcos Constandse por autorizar la publicación de esta versión en español del artículo de Knórozov.

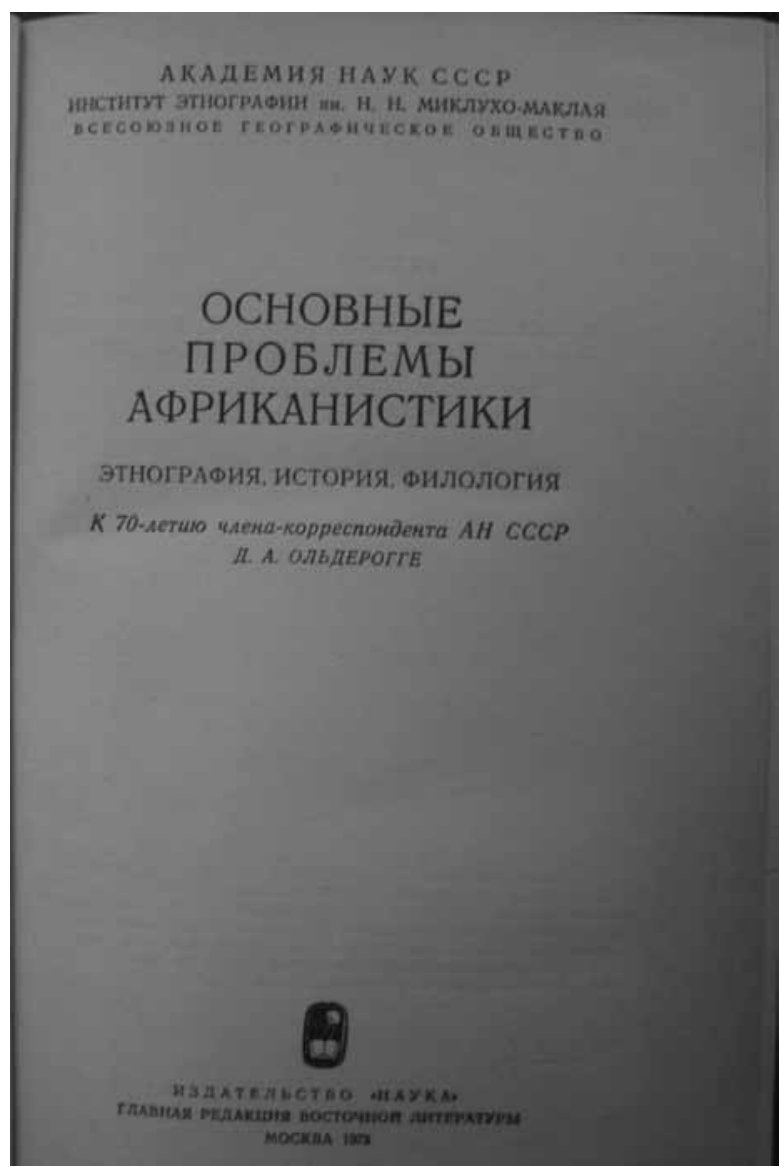

Revista LiminaR. Estudios sociales y humanísticos, año 10, vol. X, núm. 1, junio de 2012, San Cristóbal de Las Casas, Chiapas, México. ISSN: 1665-8027 

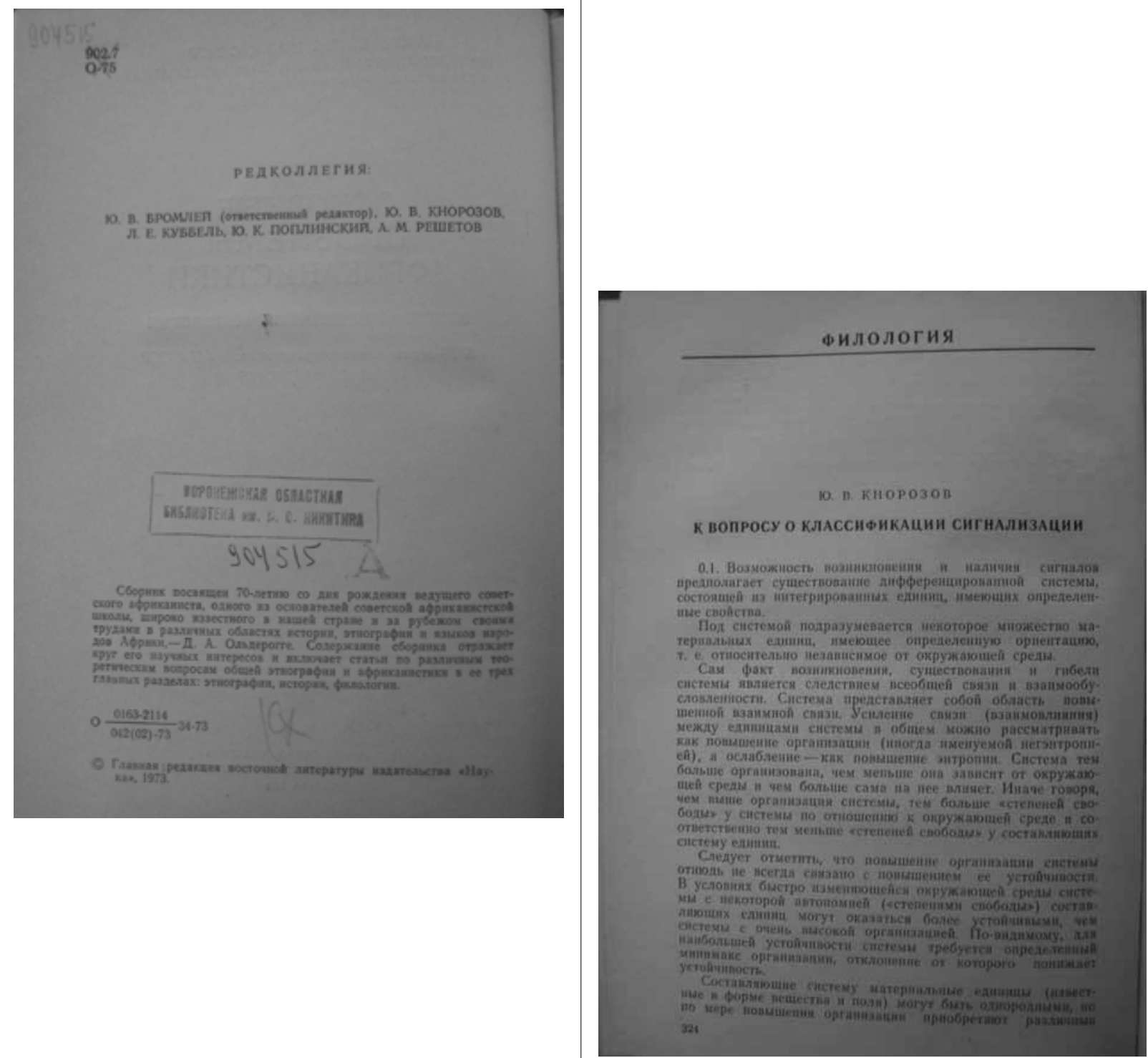


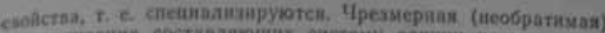

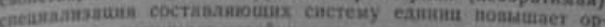

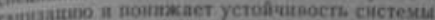

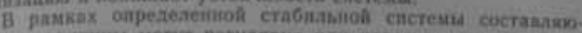

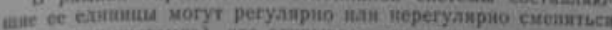

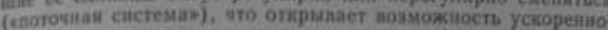

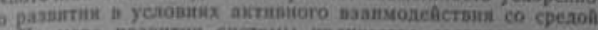

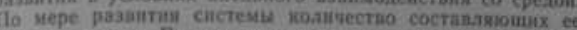

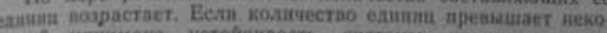

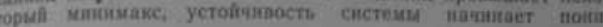

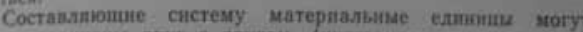

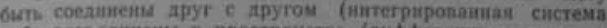

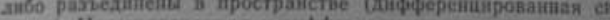
стема). Иитегрированиая ит дифференциронаная системи иа.

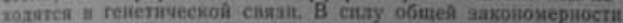

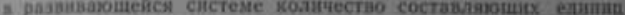

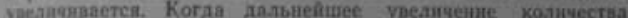

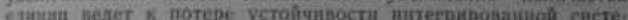

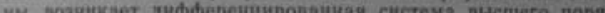

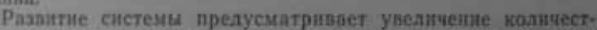

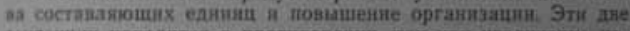

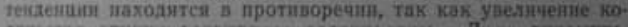

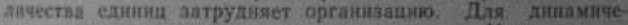
cais chстем характерно ускорешіе разантия. Mezteinoe на

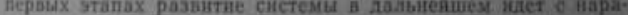

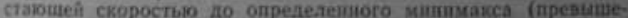

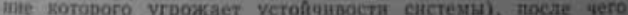

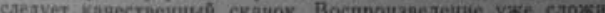

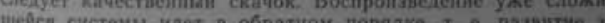
меzasetco. Tak,

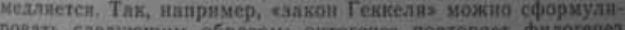
ровать следугошим образом: oitrorenеs

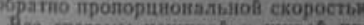

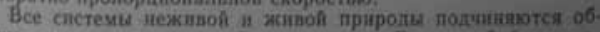

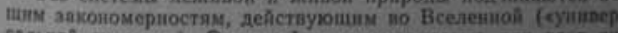

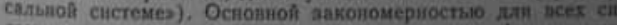

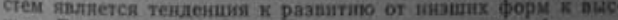

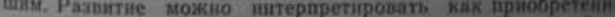

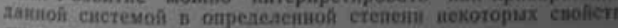
тнитерсальноi citcresus.

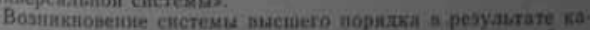

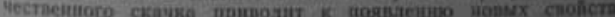

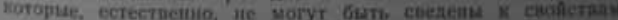

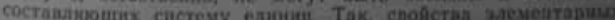

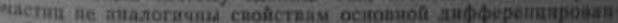

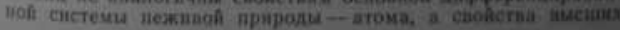

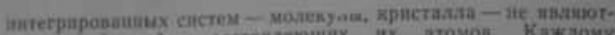

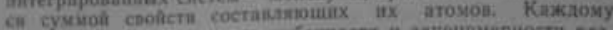

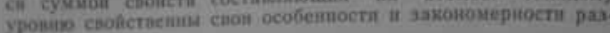
intriet.

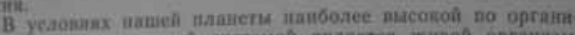

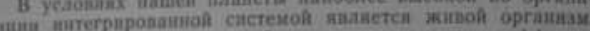

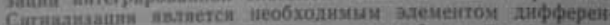

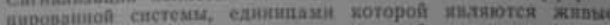

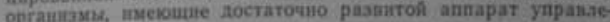

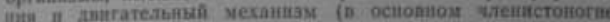
i xopasose).

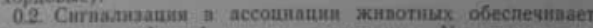

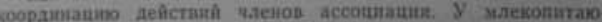

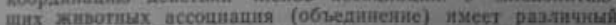

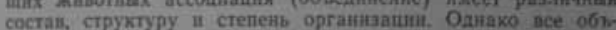

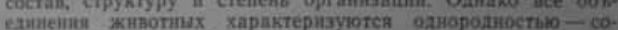

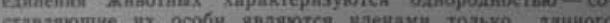

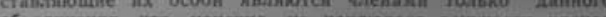
остединеная, 4то,

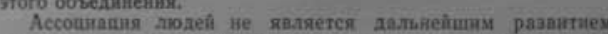

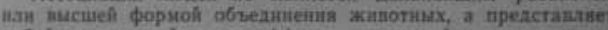

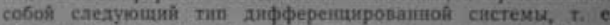

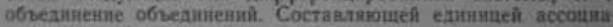

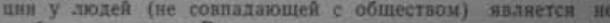

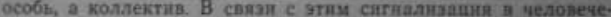
скоh accounamun of

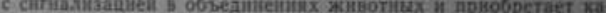

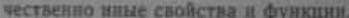

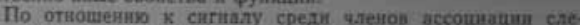

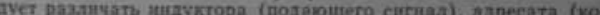

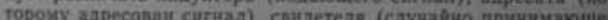

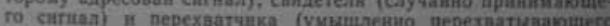

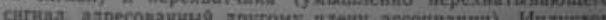

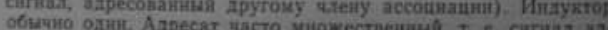

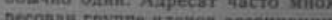

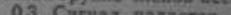

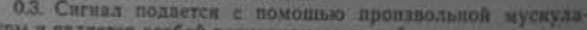

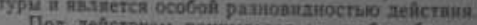

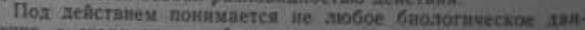

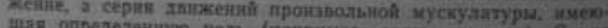

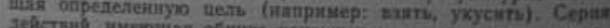

Menar

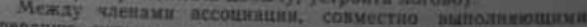

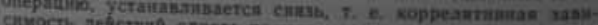

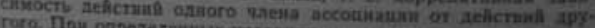

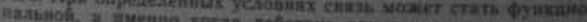

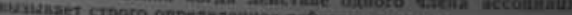
30 


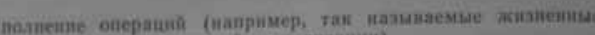

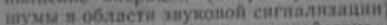

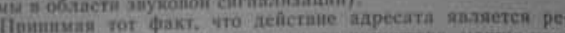

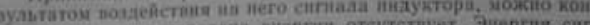

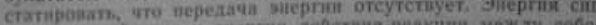

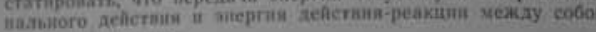
sooditte he cansanim

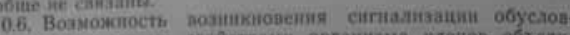

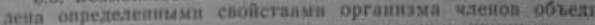

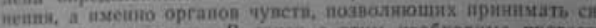

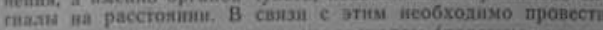

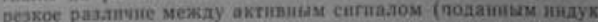

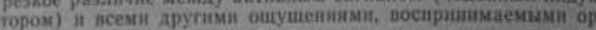
ranavin чуact aаресата.

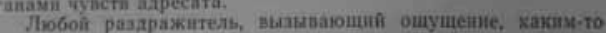

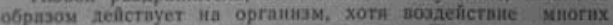
разарамителей практически нейтрально. Ліобой разаражы. тель помимо примого воздеfствин может (во вснком саучае

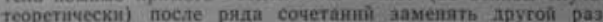

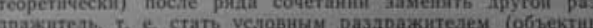

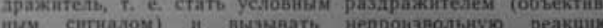

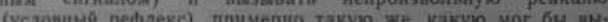

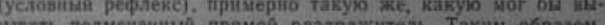
ataoar, aozmenein

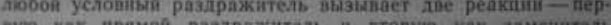
вую как арямой раздражитель apyroro прнм⿻ro paszражıтеля

Активныी ситнал, поданный индуктором, дая органов қувств адресата янляется одним из многих раздражінелеf if может рассматріваться пак пекоторая разновидиость ус

ловиого раздражители, вызывающето условиый рефлекь.

Одкако, хоти механшзм условных рефлексов широко ис

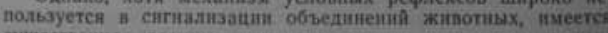
существеная разнша между пстиным ситналом и условiим раздражителем.

Условіви раздражитеаь называет иепронзвольнук реак.

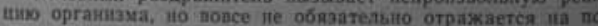

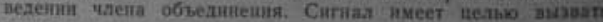

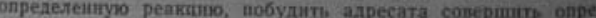

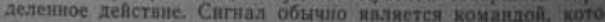

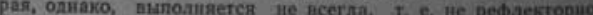

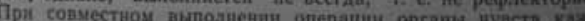

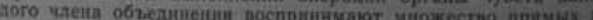

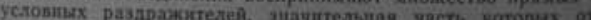

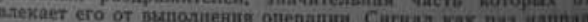
aei вротін stus noves onepaumi.

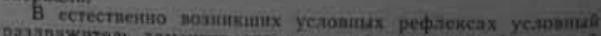

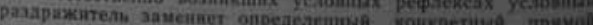
Im

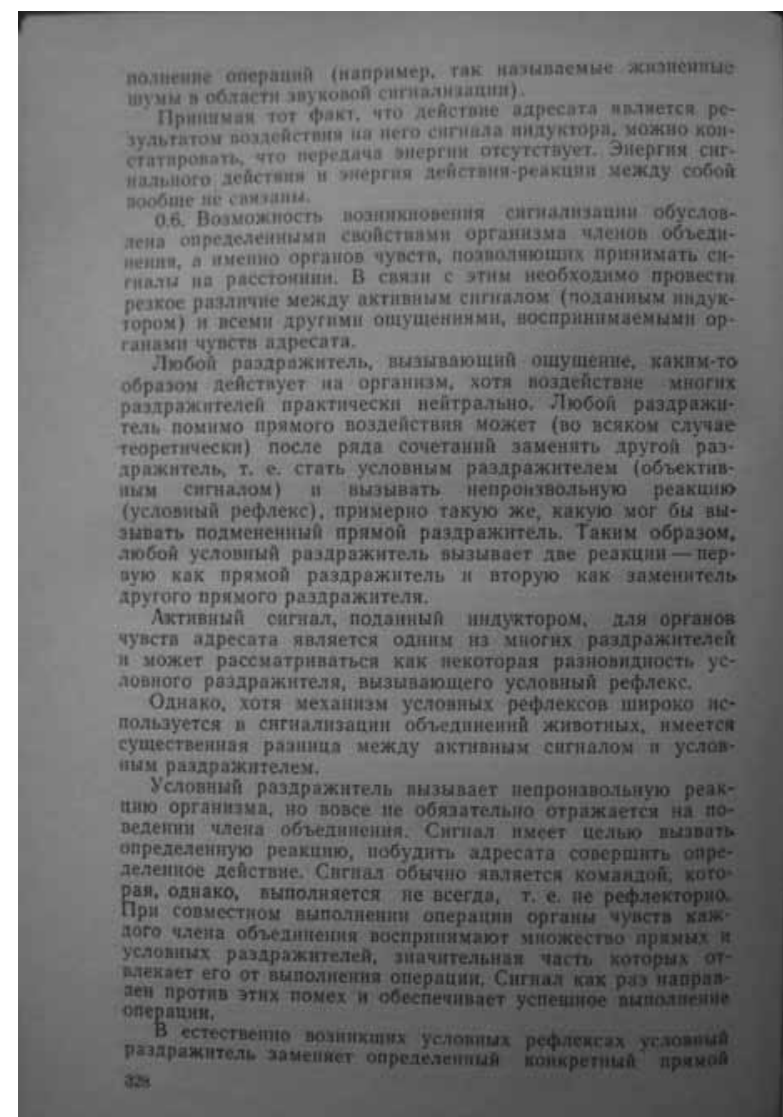




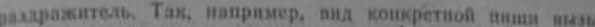

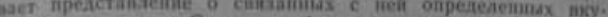

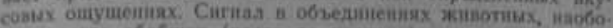
рот, всегда обобтеп (васто до предела) и имкогда іле обо.

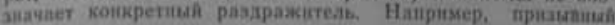

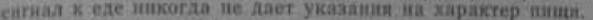

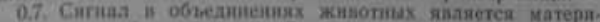

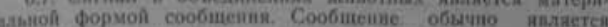
қомандой (в открыатоя или скрыстом виае). Cirrias nереянет

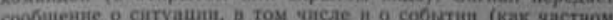

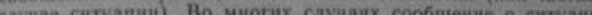

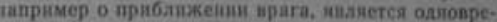

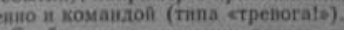

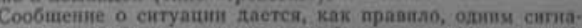

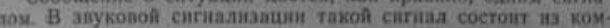

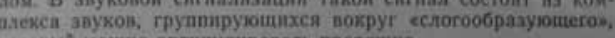
жоторый можио артнкулировать протяжно.

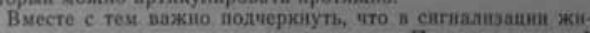

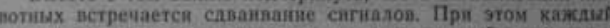

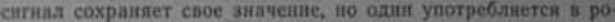

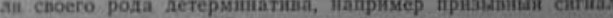
кошики к котятам, состоит нз хороткого мурлыканья, перехо дамето п мяукаиье (єблагожелательни прнана)

Встречаются служан перехпата ситиалов п обһелинени

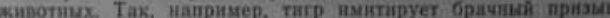

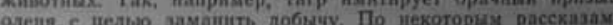
cum, ,

1.1. Перехол от объединения к внсшему типу дифферен-

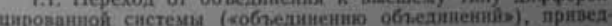

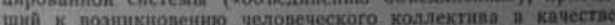

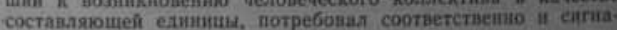
лизани вucmero тип:

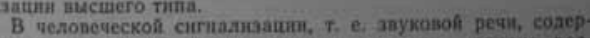

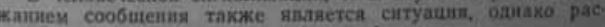
члененікан на состаamse части (трінда).

$$
\text { еубиект - дейcrum - } 06 \text { hekr }
$$

Onределеши и обстоятельство не нвлиотея чдеіами трия.

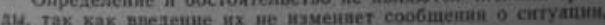
а только лает пополинтельную информанио.

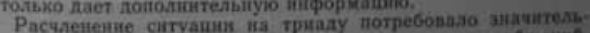

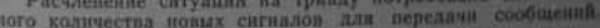

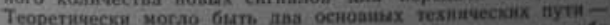

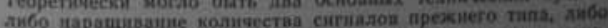

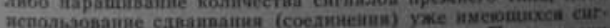

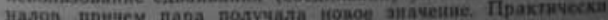

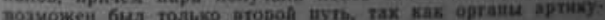

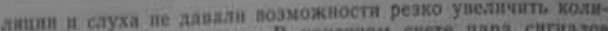

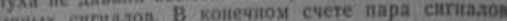

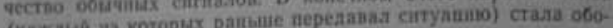
(Kazctain wa которых раты

mavirth элемент тринда.

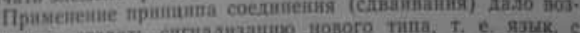

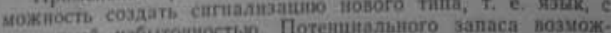

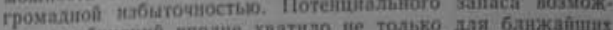
грома. "нак k0s.

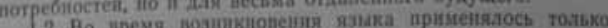

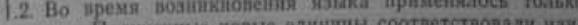

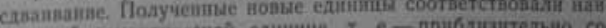

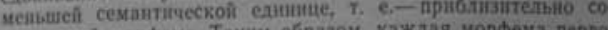
иремештоп морфеме. Таким образом, каждая морфема перьо-

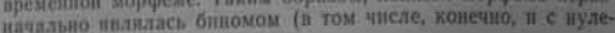
suм компонентом).

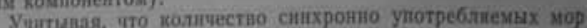
фем в . 1060 м ныке около 1600 , можно полагать, что qисто исхоликх спгналов, послужившнх матерналом для языка, быso поряыка 40 (что соответстаует пршмерно количеству сығ-

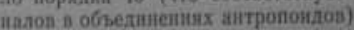

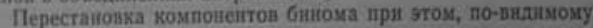
иe должна уиттываться, так как скореe всего на ранних зта:

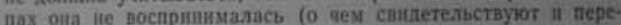
становки в раннеी детской речн).

Перногачальные единищ языка, конечно, не были мор. фемамн в современом смысле слова, а стали таковыма пі ходу разантия языка с использованнем того же прннцин со елинения, T. C. с позникновением саовоформ.

C точки зрення фонетическоî первоначальние елинит

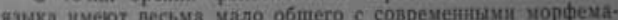
ми (хоти бы уже по различно органов артикуаяни). Далее. 4о холу развнтия языка фонетический состав морфем, насколько хожно судить, полностьо сменилея несколько раз

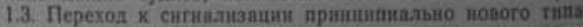

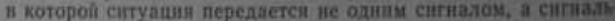

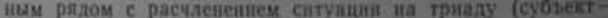

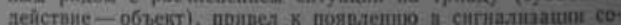
вертешн повнх кауеств.

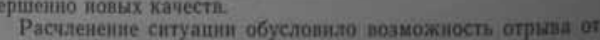
нее сштиалыного рада. До sтoro curuas sor orнocimes roik

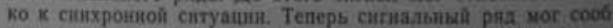

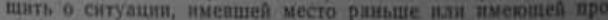
нaofru \& 6yayutes

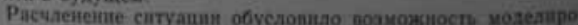

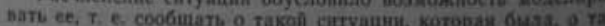

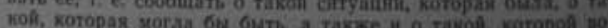
obuie ne vower burs. Пi

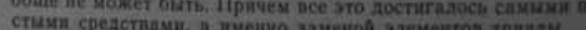

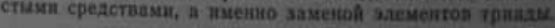
$3 \times 0$

Revista LiminaR. Estudios sociales y humanísticos, año 10, vol. X, núm. 1, junio de 2012, San Cristóbal de Las Casas, Chiapas, México. ISSN: 1665-8027 


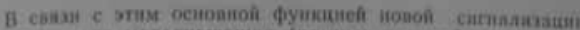

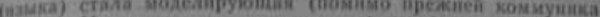

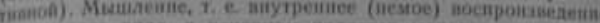

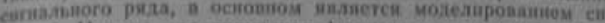

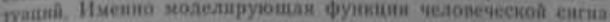

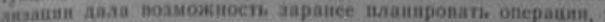

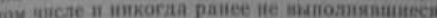

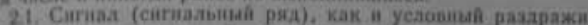

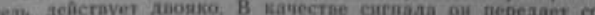

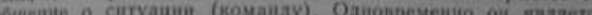
-

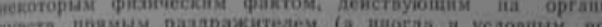

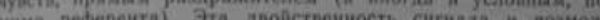

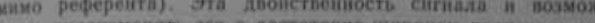

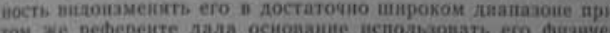

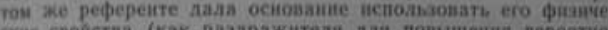
ские свопіста (как разаражитеяя дли повышеши перовто. сти виполмени команаы)

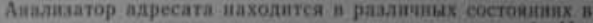

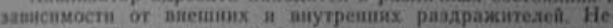
которыс разаражители, особенпо ритмически понториошиеся. врнводи $\mathrm{k}$ Некоторому затормаживаншо ана.мззатов. Такое

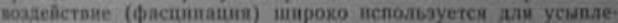

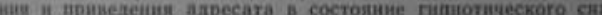

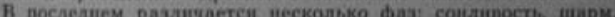

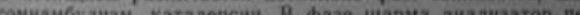
comas.

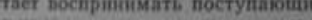

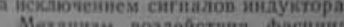

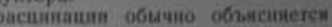

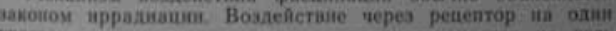

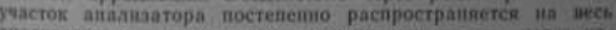
анадизатор, за нскаюченвем естороженого постал, через ко. тормй осуществанетси контакт с индуктором (ранпорт). Прв

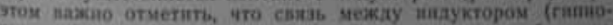

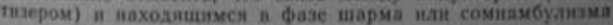
амресатом банзка $к$ функинональной, т. е. адресат выполинет

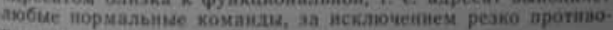
Deчautix nрактінке caoero колаектив:

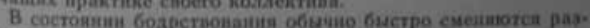

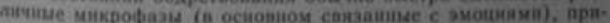

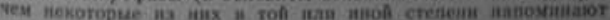

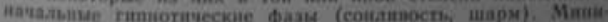

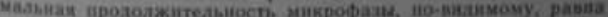

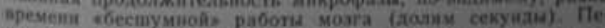

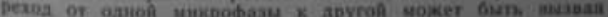

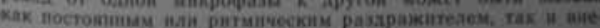

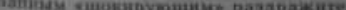

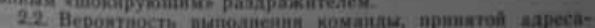

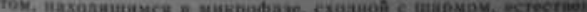

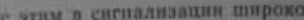

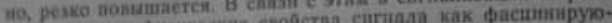

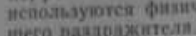

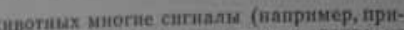

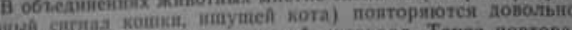

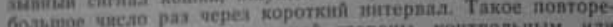

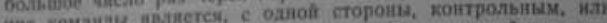
the

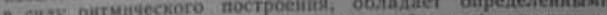
g. cи.у p.

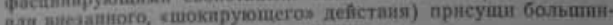

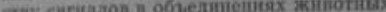

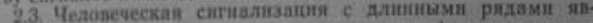

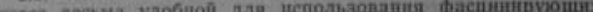

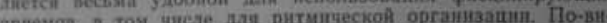

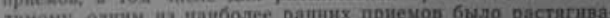

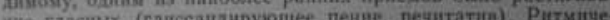

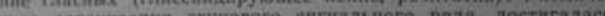

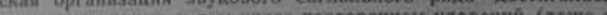

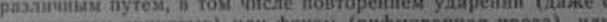
Toro il apyroro (рнффмованmue crixit)

Олиако аналиатор, неоднократио погнергаясы опредетенному ритмическому раздраженпо, перестает его воспринимать (иапример, постойное такапне степнах часов), что. очевидто, саедует квалифицировать как єпропивотормозиук

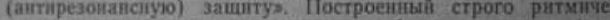
ски ситнадьный ряд может сходным образом утратить фас-

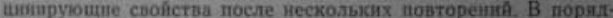

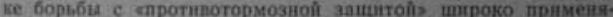
лись различиме нарутения олнобразноге ритма, например,

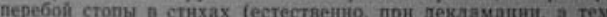

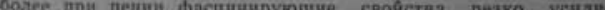
aaiorcii).

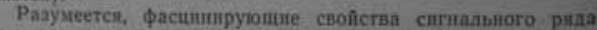

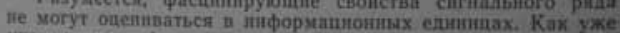

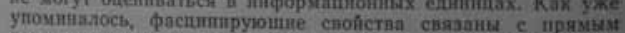

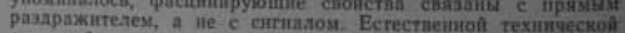

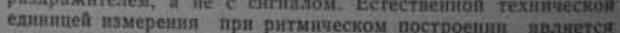
take war crorin $T$. ноль

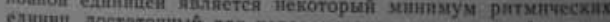

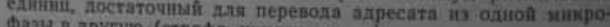
фама "I другую (строфа, куплет, мотив).

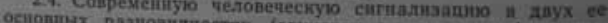

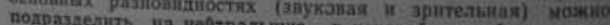

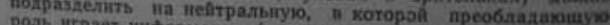

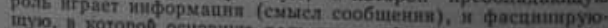
curnaanıoro pen am 


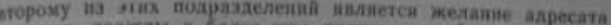

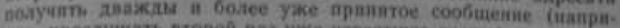

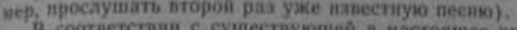

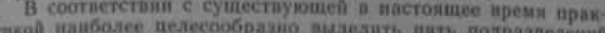
(с спмметричими расположеніем)

\begin{tabular}{|c|c|c|c|}
\hline 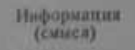 & $\begin{array}{l}\text { Dactumatua } \\
\text { (cBofterno) }\end{array}$ & 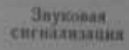 & $\begin{array}{l}\text { 3pureabuda } \\
\text { Cirntasmaun }\end{array}$ \\
\hline $\begin{array}{l}\text { 1. Reflernyer } \\
\text { 2. Aeâcroyer }\end{array}$ & 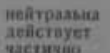 & $\begin{array}{l}\text { pequ } \\
\text { inmosanas }\end{array}$ & $\begin{array}{l}\text { тenct } \\
\text { casaurpaфua }\end{array}$ \\
\hline $\begin{array}{l}\text { 3. Aeitcrnyer } \\
\text { 4. Dencrnyer } \\
\text { sacrayito }\end{array}$ & $\begin{array}{l}\text { teficrnyer } \\
\text { selictiyer }\end{array}$ & $\begin{array}{l}\text { декамианын } \\
\text { nenate }\end{array}$ & 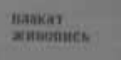 \\
\hline 5. Heátpassma & aeficrnyer: & мумава & орнамein \\
\hline
\end{tabular}

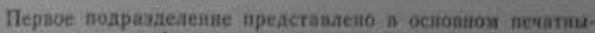

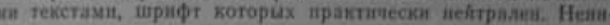
тониров (c)

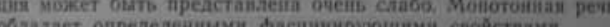

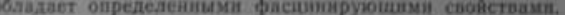

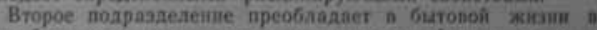

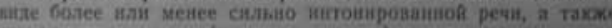

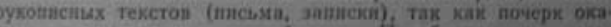

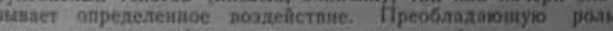

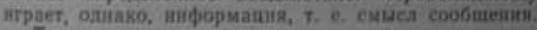

Tретье подразделение хараитернзуетси равовесием ин.

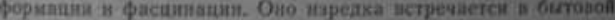

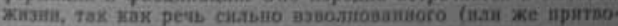

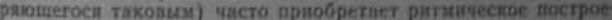

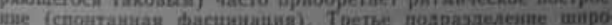

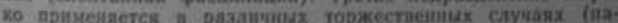

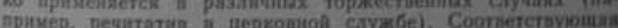

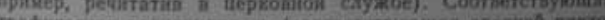

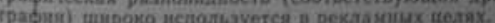

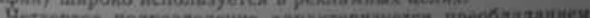

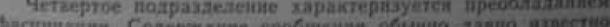

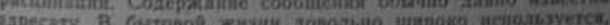

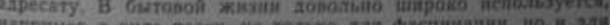

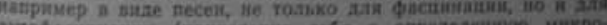

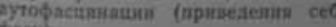
pasy

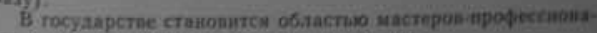

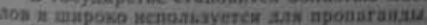

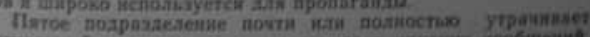

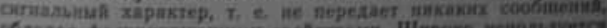

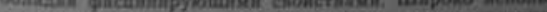

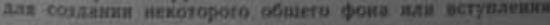

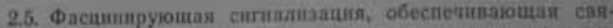

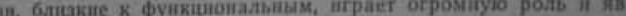

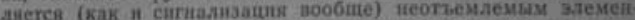

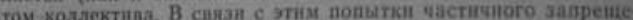

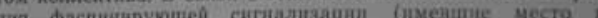

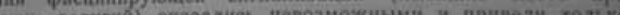

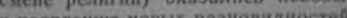

Хотя фасынаныя очень широко применяетея в области мскусства, последиее ипкак нельзя сводить к фасдінапн ін

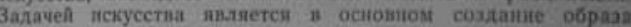
(реке сітуациі), т. е. создание у адресата представаения о аичности, которая могда бы быты положитезьвам или отрашателыны этадоном, полходяним лля слетования,

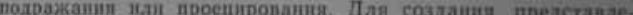

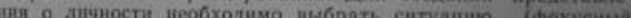
чочент), (фокусінаң кy, В

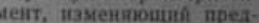

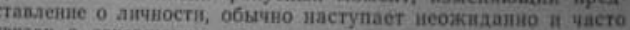

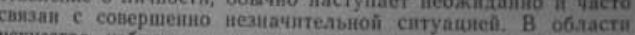
нскусства изорать сытуанию, которая была бн фокусиеа

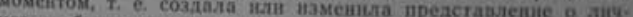
.ст, ооциiо удастси только мастерам

Если фокусиы й момент уластерам. шикает адекватиое момент уданно наран, то у адресата аол.

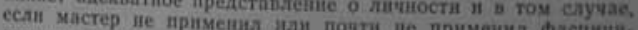

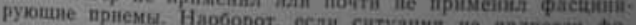

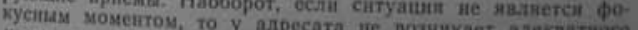

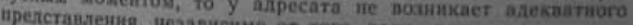
ina фасшини,

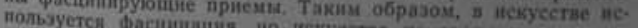

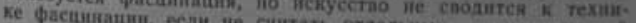
(uanpirep, opнaмearmoi). 